\title{
Advantage of Vacuum Assisted Closure on Healing of Wound After Perineal Trauma: Image of Trauma
}

\author{
N. Hamidaoui, M. Ouaïssi*, I. Sielezneff, J.B. Chaix, N. Pirro, S. Cresti, B. Consentino, B. Berthet \\ and B. Sastre
}

Service de Chirurgie Digestive et Oncologique, Pôle d'Oncologie et de Spécialités Médico-Chirurgicales, Hôpital Timone, Marseille, France

We reported a twenty years old patient with perineum injury after highway accident treated with Vacuum-Assisted Closure (VAC) therapy. The patient also had a pelvis fracture, a dislocation of the knee associated with a break leg with major loss of substance requiring associated VAC treatment. We packed the perineal cavity with four roll gauzes and Mikulicz bag, and we treated break leg by immobilization by external fixator. The first procedure has been made quickly in order to ensure the perineal haemostasis (Fig. 1a), and stabilize the hemodynamic situation. Major risk factor for delayed wound healing was smoking.

This pack was removed five days later and the $\mathrm{VAC}^{\circledR}$ was settled in place with $125 \mathrm{mmHg}$ suction. It was changed every 72 hours in operating room (Fig. 1b) the pack was removed and the $\mathrm{VAC}^{\circledR}$ system was left in place under general anesthesia. During one month all dress was made in operating room, in order to limite pain for the patient and complete tightness was obtained. For the second step during the changed packed by VAC system, lateral colostomy was performed during the same procedure. Sometimes, when the amount of count fluid was too high, we have to shorten the change period.

One month later, the setting up of a V.A.C. suction system has resolved the sepsis in a few days and accelerated the healing. A completely granulated wound, which may be covered by skin-graft for full reepithelialization was occurred at 45 day after pelvic trauma. Complete healing was achieved 60 days after the accident.

Less five percent of the perineum injury are penetrating [1]. This low frequency contrast with their gravity. This kind of injury always demonstrates a high-energy trauma: accidents on the highway, accidents at work, and falls from important heights. Severity and prognosis depend on: mechanism, lesional associations (in particular the presence of critical injuries), speed of care. The main factors are the early and effective management of haemorrhage and sepsis. Mortality from this type of disease is difficult to assess given the difference in severity of injuries. Cited mortality rates for pelvic fractures range from $3-20 \%$. One study of pelvic fractures in children aged 16 years or younger cited a mortality

*Address correspondence to this author at the Service de Chirurgie Digestive et Oncologique, Hôpital Timone, 267 rue Saint-Pierre 13385 Marseille, France; Tel: (33) 491385852; Fax: (33) 491385552;

E-mail: mehdi.ouaissi@mail.ap-hm.fr (a)

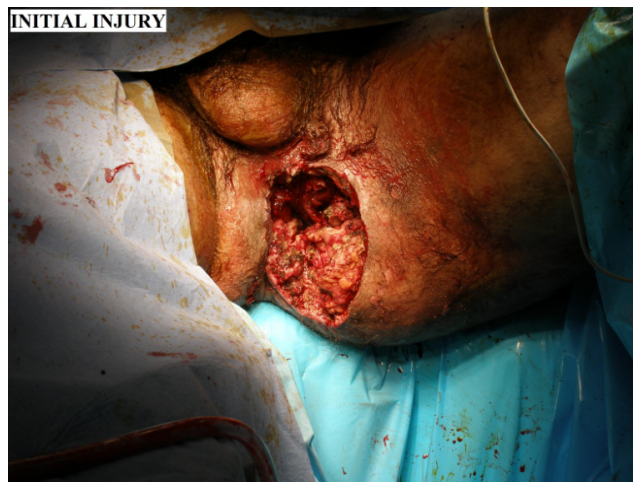

(b)

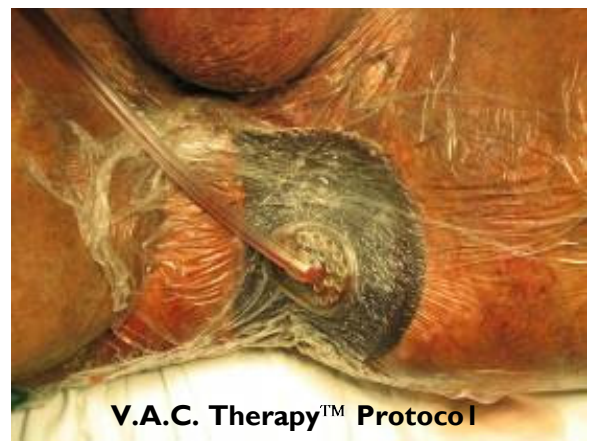

(c)

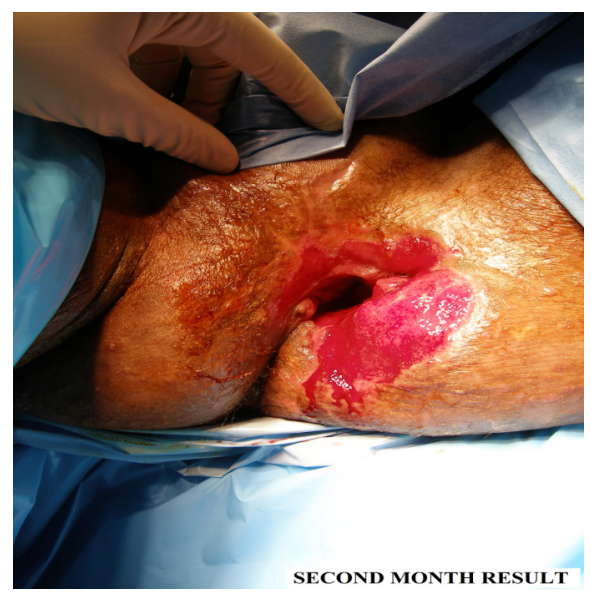

Fig. (1).

2009 Bentham Open 
rate of 5\%, with death most commonly due to hemorrhage or multiple injuries [2].

Various surgical options have been reported to manage perineal wound [3]: 1-closure with drainage; 2reconstruction with plastic surgery; 3-packing. Here, closure or plastic surgery was not possible because of sepsis and hemorrhage. Packing was necessary to stop the bleeding, but could not overcome the loss of substance and thus close the wound. The VAC:

- $\quad$ reduces edema and bacterial load,

- $\quad$ increased tissue perfusion,

- $\quad$ drains and keeping the wound wet and warm.

All these factors support the development of granulation tissue [4]. Moreover the VAC can reduce the size of the wound by bringing its banks (by the negative pressure). That is why the VAC seemed to be the key factor to get a satisfactory result. This system has more than its clinical benefits. It appears to be safe, effective and convenient to the patient and nursing staff. In recent study by Labler and colleagues VAC therapy was used in pelvic trauma requiring multiple operative debridement and consequently an appropriate temporary dressing [5]. In view of theirs results, the management of the large tissue defects in pelvic regions by means of $\mathrm{VAC}^{\mathrm{TM}}$ as a temporary coverage positively supports wound conditioning, reduces infectious complications, and facilitates a definitive wound closure.

The study reported by Stawiky and colleagues confirmed the efficacy of VAC in pelvic Vacuum-based therapy appears to be safe, effective, and convenient to the patient and nursing staff, and allows for less frequent dressing changes and better quantification of fluid loss from the wound [6]. It can reduce the length of hospitalization and thereby reduce costs of care.

In conclusion, in view of all these facts VAC seems to be an indispensable tool for the management of complex perinea wounds.

\section{ACKNOWLEDGEMENT}

We are grateful to Dr. Ali Ouaissi, Head of Research at INSERM (UMR CNRS 5235, Université Montpellier 2, France) for critical reading of the manuscript.

\section{REFERENCES}

[1] Davidson BS, Simmons GT, Williamson PR, Buerk CA. Pelvic fractures associated with open perineal wounds: a survivable injury. J Trauma 1993; 35: 36-9.

[2] Ismail N, Bellemare JF, Mollitt DL, et al. Death from pelvic fracture: children are different. J Pediatr Surg 1996; 31: 82-5.

[3] Cresti S, Ouaïssi M, Sielezneff I, et al. Advantage of vacuum assisted closure on healing of wound associated with omentoplasty after abdominoperineal excision: a case report. World J Surg Oncol 2008; 6: 136.

[4] Durmishi Y, Gervaz P, Bühler L, et al. Vacuum-assisted abdominal closure: its role in the treatment of complex abdominal and perineal wounds. Experience in 48 patients. J Chir (Paris) 2007; 144(3): 209-13.

[5] LablerL, Trentz O. The use of vacuum assisted closure VAC(trade mark) in soft tissues injuries after high energy pelvic trauma. Langenbecks Arch Surg 2007; 392: 601-9.

[6] Stawicki SP, Schwarz NS, Schrag SP, et al. Application of vaccum assited therapy in post operative ascetic fluid leaks: an integral of multimodality wound management in cirrhotic patients. J Burns Wound 2007; 6: e7. 